\title{
Communicative Competence and the Architecture of the Mind/Brain
}

\author{
Maurizio Tirassa \\ Centro di Scienza Cognitiva, Università di Torino, Torino, Italy
}

\begin{abstract}
Cognitive pragmatics is concerned with the mental processes involved in intentional communication. I discuss a few issues that may help clarify the relationship between this area and the broader cognitive science and the contribution that they give, or might give, to each other. Rather than dwelling on the many technicalities of the various theories of communication that have been advanced, I focus on the different conceptions of the nature and the architecture of the mind/brain that underlie them. My aims are, first, to introduce and defend mentalist views of communication in general; second, to defend one such view, namely that communication is a cognitive competence, that is, a faculty, and the underlying idea that the architecture of the mind/brain is domain-specific; and, third, to review the (scarce) neuropsychological evidence that bears on these issues. (c) 1999 Academic Press
\end{abstract}

\section{INTRODUCTION}

Cognitive pragmatics is concerned with the mental processes involved in intentional communication, that is, with the characteristics of the mind/brain that allow individuals belonging to the human (and possibly to other) species to intentionally communicate with each other. A theory in cognitive pragmatics aims at describing, on a chosen level of analysis, what goes on in the mind of an agent who engages in a communicative interaction with another. The roots of this perspective may be traced to a mentalist reading of work done by philosophers of language like Austin (1962), Grice (1989), and Searle $(1969,1979)$ and to subsequent formalizations of speech acts theories in logic, computational linguistics, and artificial intelligence.

There are two main assumptions behind these approaches. The first is that

I am grateful to Brigitte Stemmer for encouraging me to dive into this ocean and to Gabriella Airenti, Bruno G. Bara, and Francesca M. Bosco for reading and commenting on the first version of the article. This research has been supported by the Italian Ministry for University and Scientific and Technological Research (MURST 40\% Program Nuovi paradigmi per l'interazione e nuovi ambienti di comunicazione, 1995-1997).

Address correspondence and reprint requests to Maurizio Tirassa, Centro di Scienza Cognitiva, Università di Torino, via Lagrange 3, 10123 Torino, Italy. E-mail: tirassa@psych.unito.it. 
communication is best viewed as one form of social activity and that a theory of communication belongs therefore to the study of action and social action rather than of language or of the transmission of information. The second is that communication involves some form of active cooperation between the participants.

Several theories can be and have indeed been developed within this framework. However, to view intentional communication as part of the mental events and the interactions with the (social) world actually entertained by real human beings imposes the further requirement that one's specific research be framed within some broader conception of the nature and functioning of the human mind. This constraint is not necessarily as compelling in philosophy, in logic, or in artificial intelligence: cognitive pragmatics is thus developing as an autonomous perspective, related but not reducible to its antecedents. Theories in this area have been advanced, among others, by Airenti, Bara, and Colombetti (1993), Clark (1996), Kasher (1976, 1991a,b), Sperber and Wilson (1986), and Tirassa (1997).

In this article I discuss a few issues that may help clarify the relationship between cognitive pragmatics and the broader cognitive science and the contribution that they give, or might give, to each other. Rather than dwelling on the many technicalities of the various theories that have been advanced, I focus on the different conceptions of the nature and the architecture of the mind/brain that underlie them. My aims are, first, to introduce and defend mentalist views of communication in general; second, to defend one such view, namely that communication is a cognitive competence, that is, a faculty, and the underlying idea that the architecture of the mind/brain is domain-specific; and, third, to review the (scarce) neuropsychological evidence that bears on these issues.

The next section introduces a few themes in mentalist pragmatics that are relevant for my subsequent discussion. In "Intentional Cognitive Architectures" I propose an interpretation of the reasons for casting a cognitive theory of communication in terms of the (types of) mental states that an agent has to be able to entertain in order to engage in communication with a partner; the broader architecture of cognition is defined in similar terms. In "Communicative Competence" I come back to pragmatics, focusing on its integration within a domain-general or a domain-specific view of cognition and arguing in favor of the latter choice. Communication is then defined as competence; that is, as a specific cognitive faculty that requires dedicated components of the cognitive architecture. In "A Theory of Communicative Competence"' I outline a theory of communicative competence and of its innate components. In "Neuropragmatics" I make a few proposals for the empirical investigation of the main topics touched on in the preceding sections, based in part on a reconsideration of the existing neuropsychological literature. 


\section{MENTALIST THEORIES OF COMMUNICATION}

Grice (1957) defines communication as an overt interaction between two (or more) agents, one meaning something by a certain action in a certain context and the other inferring from the observation of that action to its presumed communicative meaning. Communicative meaning is in turn conceived of as the effect that the first agent overtly intends to achieve on the partner's mental processes.

Suppose that, while Bob is dressing to go to work, Ann looks out of the window and says "I think it's about to rain" and that Bob then decides to take an umbrella with him. ${ }^{1}$ In Grice's account, as spelled out by Strawson (1964), this is a case of (successful) communication if Ann, by her utterance: (1) intends to induce Bob to take an umbrella; (2) intends Bob to recognize intention (1); (3) intends such recognition to be (part of) Bob's reason for taking an umbrella; and if Bob recognizes Ann's intentions [1-3] in his turn.

This analysis is rightfully regarded as the starting point of contemporary theories of communication. Let us now consider the kind of explanatory framework it offers, postponing to a later section, a discussion of a technical drawback it presents.

The key feature of Grice's account is that it is cast in mentalist terms: from the viewpoints both of the external observer and of the agents described, communication is conceived of as a mental phenomenon rather than as mere behavior. The analysis is concerned with Ann's and Bob's respective thoughts, to which their perceivable behaviors only provide a hint.

To take this perspective brings to several interesting consequences. The first is that if communication is to be regarded as a type of action aimed at affecting a partner's mental states, then the specific means used to that end are hardly relevant as long as they are appropriate, that is, as long as the partner may still use them as clues to the reconstruction of the agent's intentions. From the standpoint of a theory of communicative agency, language in the human species is but one of a vast panoply of expressive means, on a par with various kinds of gestures, drawings, and other external codes (which is not to deny that each code has unique features): Ann could have opted for many other possible utterances or nonlinguistic actions, such as simply handing Bob the umbrella with a smile.

Second, to understand a communicative act becomes a matter of abduction rather than deduction. Bob's problem is, given Ann's behavior, should I consider it as communicative, for a start? And why has she acted like that? What stance should I take toward what she has meant? His interpretation of Ann's action as a suggestion to take an umbrella will, by necessity, be uncertain:

${ }^{1}$ Individual agents are referred to in the feminine; in the case of communication, the feminine is used for the first agent involved and the masculine for the other(s). 
for what he knows, she could have meant something very different like, say, "you don't need to water the flowers today."

Third, mere comprehension is but the first step to successful communication: Ann does not utter her sentence for the sake of it, but with the aim of modifying Bob's mental states, and it is this final outcome that will provide the measure of her success. What counts as success, furthermore, is not obvious: Ann's goal is probably that Bob avoids gets drenched with rain rather than specifically that he takes an umbrella so that other reactions on his part (e.g., to call for a taxi, to wear a raincoat, or to simply give up to get out) might as well satisfy her.

These considerations explain the intricacies of doing empirical research in this area. Since pragmatic inferences can never be safe, the concept of a correct answer (or, in general, of a good performance) can only be defined very loosely; to evaluate the communicative skills of an individual is accordingly difficult.

However, what is most important to our current discussion is that, on a mentalist account, communication and language are decoupled from each other. The study of communication falls no more in the domain of linguistics: far from being concerned with "language use," it becomes part of the study of agency and social agency. This opens the way in turn to the idea (that is defended in a later section) of a communicative competence, conceptually distinct from other cognitive faculties as well as from language and the other means of expression - though obviously related to them when performance is considered.

\section{INTENTIONAL COGNITIVE ARCHITECTURES}

\section{Intentionality and Intentional Primitives}

In Grice's definition, an interaction between two agents is an instance of communication when one of them entertains a certain, precisely definable set of mental states [namely, intentions (1), (2), and (3) above] and the other entertains, as a consequence of the first agent's relevant behavior, a certain other [namely, the belief that she entertains intentions (1), (2), and (3)].

A framework of this kind, called an Intentional one and founded on the concept of mental states, is unusual in cognitive psychology and neuropsychology; nonetheless, it has become the common choice of most current theories of pragmatics, whether they take a philosophical, logical, computational, or psychological perspective. ${ }^{2}$ Remarkably, it has also been widely

${ }^{2}$ Let me remind that the word intentional and its derivatives have two meanings. One corresponds, roughly, to semantic, or representational, and applies therefore to any mental state endowed with content, like a perception, a belief, a fear, or a desire. The other refers instead to a specific class of such states, namely, intentions, that are relative to action planning and execution. For the sake of clarity, I capitalize the initial " $I$ ', when using the former acceptance. 
adopted in recent years for research on high-level agency in cognitive science, artificial intelligence, and distributed artificial intelligence, where talk of BDI (belief-desire-intention) architectures is currently standard (e.g., Rao \& Georgeff, 1992). This is particularly telling, since studies in this area used to adopt instead a more classic information-processing stance, until it became clear that planning and deliberation are better treated in a mentalstates framework (Bratman, 1987; Cohen \& Levesque, 1990a; Pollack, 1990).

In general, Intentional approaches prove the most fitting for the development of theories aimed at capturing the complexity of an agent's interactions with the real world. Concepts like plan, expectation, or preference or whole stories like Ann went to the movies because she was bored with staying at home are hardly reducible to the coding, the processing, and the storing of information. They build instead on a conception of the mind as representing a whole subjective situation, whose every detail only makes sense within the broader picture, and on a view of the agent's decisions and actions as conscious, purposeful movements within this complex landscape in search of an improvement to the current situation.

The same holds for social interactions: concepts like assert/reply and promise/accept or cooperation (or lack thereof) and teamwork as well as the umbrella episode we have seen above only make sense if the mental states of the agents involved are taken into account-witness also the difficulty to define the difference between, say, beg, borrow, and steal in a behavioral or an information-processing framework.

Concepts and stories like these are instead more naturally decomposed into simpler situations, decisions and actions of the same general type, like Ann picked up the newspaper to see what movies were on that day. Thus, Intentional theories build ultimately on what may be called Intentional primitives, that is, the types of mental states, of contents for them, and of transitions from one state to another that are characteristic of a certain agent, or species of agents, under certain circumstances.

It has been argued against Intentional terminology that it belongs to "folk psychology" and should therefore be banned from the scientific study of cognition (Churchland, 1984, 1988; Churchland, 1986; Stich, 1983). Concepts like belief or intention, though, cannot render a theory of psychology more "folk" than the concepts of force, field, or reaction can with theories of physics or chemistry. While the everyday acceptation of all these terms may often be vague, each also has a technical meaning (possibly rooted somehow in the "folk" one) that can be defined with better precision and adopted in scientific theories in psychology as in physics or chemistry.

However, there is little consensus in cognitive science as to the precise meaning of Intentional terms. My acceptation is that mental states are conscious representations of the world as it, from the agent's subjective point of view, is, was, or could be. For an agent to entertain a certain mental state 
is for her to be in a certain semantic relation to the world; the various types of mental states that she may entertain are therefore defined according to the different types of semantic relations that she may have with the world (Searle, 1983). Theories may thus be formulated where, for example, beliefs encode the agent's knowledge of the situation at a given time, desires encode her potential goals, intentions encode her actual goals, and so on.

The entities that an agent's mind is sensitive to and able to representin Intentional terms, the possible contents of her mental states-make up her subjective ontology (Tirassa, Carassa, \& Geminiani, in press). This may comprise different types of objects, relations, events, and actions. The subjective ontology of a highly sophisticated social species like ours will also comprise social objects (individual agents, groups, etc.) along with their features (beliefs, intentions, etc.) and the relations, events, and actions that they may participate in (staying at home, going to the movies, etc.).

\section{Mind/Brain Dynamics}

An agent's mind at any slice of time can now be described as a set of mental states with their contents, like Ann is bored with staying at home or Bob believes that Ann believes that it is about to rain. Since an adaptive mind/brain has to keep tightly coupled to a world that is dynamic, however, it is better described as whole sequences of mental states across time than as isolated, instantaneous states. Let us call such sequences cognitive dynamics (Tirassa, 1997).

Once unfolded, the umbrella episode of "Mentalist Theories of Communication" reports two such dynamics that, taken together, provide the set of events that a theory of communication is expected to describe and explain. One dynamics is Ann's: she looks out of the window, notices that there are clouds in the sky, forms the expectations that it will rain and that Bob will get wet, decides to suggest to him to take an umbrella, and finally plans and executes a suitable communicative act. As for Bob, he is dressing and probably minding his own business, but immediately shifts his attention toward Ann, reads her behavior as communicative, comprehends it, reflects upon its meaning, makes up his mind in accordance, and finally decides to take an umbrella and maybe to thank Ann for her kindness. Clearly, these events are intimately tied to each other: each is caused by the one that immediately precedes and causes in its turn the one that will immediately follow. Where does this causality come from?

Unless one is willing to be a dualist and to accept the problems that then follow, consciousness and Intentionality have to be conceived as material properties of an agent's functioning brain-hence talk of mind/brain, rather than mind (or brain) alone, throughout this article. Like all the material properties of a physical object, the state of an agent's mind/brain at any slice of time will therefore play a causal role in the state of her mind/brain at the following slice of time, together with cooccurring factors that may affect this functioning, like the activity of sensory receptors or of a drug. 
An agent's cognitive dynamics across time thus results from the interaction of her mind/brain with the surrounding (mental, bodily, physical, and social) environment. The specific pattern of this interaction is rooted in turn in the phylogenetic and ontogenetic events that have shaped the agent's mind/brain.

\section{Cognitive Architecture}

We can now define the architecture of an agent's mind as the set of cognitive dynamics she may entertain; communication, as we will see in the next section, is one such dynamic.

It can clearly not be the goal of cognitive science to describe each and every particular mental state or cognitive dynamic an agent may entertain, that is, to list the whole set of her possible thoughts; nor can it be the goal of a theory in pragmatics to describe each and every possible instance of communicative interaction. That would correspond to conceiving of the goal of, say, linguistics as the list of all the possible sentences in all the possible languages, an idea that has been repeatedly proved absurd.

Something more general is needed. The solution, in pragmatics as in linguistics or in cognitive science at large, is to describe the system under study as the engine that is capable of generating all and only the relevant mental phenomena, be they instances of communicative interaction, sentences, or whatever. As far as mentalist theories of pragmatics are concerned, this corresponds to describing what I have called the Intentional primitives of a communicating mind. In this interpretation, it is the aim of such theories to provide an abstract (that is, not extensional, or conceptually dependent on specific examples) definition of communication as the type of cognitive dynamic that a certain agent (or species of agents) will entertain in a certain type of situation.

Each mentalist theory of pragmatics can therefore be distinguished according to what cognitive dynamic it defines as communication; that is, to precisely what Intentional primitives it takes to underlie communication and in what type of situation it takes those primitives to participate. This will, by necessity, build on some specific view of human cognition: each theory can thus be located within the various debates on the nature and the architecture of the mind/brain. In this perspective, the issue that is most crucial to the relationships between pragmatics and cognitive science at large (and therefore the one that will be discussed here) is the view of communication as competence or performance.

\section{COMMUNICATIVE COMPETENCE}

\section{Domain-General vs Domain-Specific Views of Cognition}

A mental phenomenon is called a competence (e.g., Chomsky, 1980) when it is conceived of as yielded by the functioning of a mental organ, that is, 
of an innately dedicated part of the mind/brain. Human language has been considered a prototypical example for 4 decades now, at least as far as grammar is concerned. In recent years, several theories have been proposed that posit the existence of other faculties, from face recognition to deontic reasoning and social exchange, thus giving rise to a lively debate between domaingeneral and domain-specific views of cognition.

The domain-general stance postulates the existence of a core, or central, cognitive system, whose functioning is characterized by general principles of cognition that are independent of whether their specific content regards communication or, say, physical causality. These principles hold across the different domains where the mind operates and may be formulated, e.g., as general laws of cognition (in the fashion of Sperber \& Wilson's, 1986, principle of relevance, or of Newell's, 1990, proposal of SOAR) or abstract inferential schemes (like those found in Newell \& Simon's, 1972, or JohnsonLaird's, 1983, theories of human reasoning). Fodor's thesis of the language of thought $(1975,1983$; Fodor \& Pylyshyn, 1989) is paradigmatic of this perspective.

The other side of the controversy holds instead that the mind operates with different principles in each domain because the ways of interpreting the world and acting in it that constitute adaptive cognition in one domain are unlikely to keep their utility in another so that no "adaptivity-preserving", generalization is guaranteed to hold across domains. The search for general laws of cognition is therefore doomed to fail unless such laws are formulated so vaguely as to lose much of their scientific interest. The study of the architecture of cognition should consequently follow the natural decomposition of the mind/brain into specialized organs rather than an abstract, unwarranted decomposition into allegedly general-purpose perceptual, storing, reasoning, and acting subsystems.

There is no room here to provide a review of the debate; suffice it to say that, in my view, theoretical considerations (Cosmides \& Tooby, 1994a; James, 1890; Minsky, 1985; Pinker, 1997) as well as empirical findings in evolutionary psychology (Barkow, Cosmides, \& Tooby, 1992; Cosmides \& Tooby, 1994b) and in developmental psychology (Hirschfeld \& Gelman, 1994; Karmiloff-Smith, 1992; Spelke, 1994) strongly suggest a decentralized, faculty-based view of cognition.

A domain-specific perspective is also in better agreement with current advancements in neurosciences, providing increasing evidence against the idea that vast areas of the brain may be dedicated to the sort of unspecific, equipotential processing that is definitional of a centralized architecture.

Let us define a domain as a specific type of interaction between an agent and its subjective environment, or, circularly, as the class of problems that admit of a certain class of solutions. Communication seems a natural candidate for this definition. The idea of a distinct communicative competence, however, has been taken into little account: implicitly or (more seldom) ex- 
plicitly, and with very few exceptions, most researchers view communication as just an aspect of the functioning of a general-purpose cognitive system (e.g., Cohen \& Levesque, 1990b; Kasher, 1991a,b; Sperber \& Wilson, 1986; Wilson \& Sperber, 1991).

It is the aim of the rest of this section to argue in favor of a competence view of communication. Communicative competence does not have to be similar in nature to the Universal Grammar that has been hypothesized for language. Rather, the problem of whether communication should be viewed as a faculty may be reframed within the metatheoretical perspective outlined in the previous sections as the problem of whether it requires a dedicated cognitive dynamic. The issue requires a little bit of technical discussion.

\section{The Problem of Common Knowledge}

Communication is a form of social interaction; in particular, it is a type of overt interaction between two (or more) agents, one meaning something by a certain action and the other(s) abducting to its presumed meaning. Since each party knows that the first agent relies, on making her move, on the partner's ability to comprehend it and each also knows that both know that she does, communication is somehow a circular process. This circularity is generally captured as the idea that communication requires that some knowledge be shared among the participants, but there are crucial differences as to the details of this idea.

Let us reconsider the umbrella episode of "Mentalist Theories of Communication": Ann glances out of the window and says "I think it's about to rain'; Bob then decides to take an umbrella with him. According to Grice (1957), as we have seen, this is an instance of communication if Ann, by her utterance: (1) intends to induce Bob to take an umbrella- or anyway to act so as to avoid getting drenched with rain; (2) intends Bob to recognize intention (1); (3) intends that recognition to be (part of) Bob's reasons for taking an umbrella; and if Bob recognizes Ann's intentions [1-3] in his turn.

Strawson (1964) remarks that a further condition is needed to rule out certain noncommunicative counterexamples, namely that Ann: (4) intends Bob to recognize intention (2).

Schiffer (1972) then shows that even this will not do and that it is also necessary that Ann: (5) intends Bob to recognize intention (3); (6) intends Bob to recognize intention (4); (7) intends Bob to recognize intention (5); and so on ad infinitum so that true communication will only occur when the first agent has, for each $n$th intention of this type, an additional $(n+1)$ th intention that $n$ be recognized by the partner and when the latter recognizes each of these $(n+1)$ intentions in his turn. The virtual endpoint of this infinite succession of mental states is called mutual knowledge and is supposed to provide the firm ground that the interlocutors need to rely on if they are to communicate safely. 
There are, however, serious problems with Schiffer's argument. First, even the simplest communicative act would require an infinite stream of intentions on the one side and a correspondingly infinite stream of acts of recognition on the other side. Obviously, neither feat could be accomplished by a realworld agent (Clark \& Marshall, 1981). Furthermore, each agent could safely rely on common knowledge only if the partner actually entertained all the relevant mental states, which would in turn require the existence of a suitable confirmation procedure plus infinite time to implement it. Once again, neither condition could ever be satisfied in the real world (Sperber \& Wilson, 1986).

We are thus faced with a dilemma. On the one hand, any conception of common knowledge as the endpoint of an infinite conjunction of nested mental states of the Ann believes that Bob believes that Ann ... kind is untenable. On the other hand, to limit the chain to an arbitrarily finite length (as proposed by Grice himself, 1982) or to simply do away with common knowledge and let condition (1) be sufficient for the definition of communication (as proposed by Sperber \& Wilson, 1986) would not rule out Strawson's and Schiffer's counterexamples, so that the difference between what is communication and what is not would be missed.

\section{Intentional Primitives for Communication}

A solution to this problem can be found in a work by Airenti, Bara, and Colombetti (1993). They acknowledge the crucial role played in communication by common knowledge, but view it as neither an unattainable ideal, nor as an objective fact to be indefatigably assessed. Rather, they define common knowledge as a primitive mental state type called shared belief: an agent shares the belief that $p$ with a partner if she believes both that $p$ and that the partner shares the belief that $p$ with her.

Shared belief, when conceived of as a subjective mental state type, turns out to be ontologically on a par with (and therefore irreducible to) private beliefs. The relationship between the two mental state types is inferential. For instance, if I am aware that you and I have been copresent to a certain conspicuous event (call it $p$ ) like, say, Ann uttering "I think it's about to rain,' I can legitimately infer that I share with you that $p$. Reciprocally, if I share with you that $q$, then I can legitimately infer that you believe that $q$, that you share that $q$ with me, that you believe that I believe that $q$, and so on. On this account, the drawback in the classic formulation pointed at by Clark and Marshall (1981) is avoided, while the circular nature of mutuality is preserved.

The status of shared beliefs is analogous to that of private ones also from the epistemological point of view. Since sharedness is a matter of attribution, an agent has neither the necessity nor the possibility to know what is "objectively" shared with a partner. Sharedness does not require fancy abilities like telepathy or an endless circularity of confirmations; nor does it require 
any more reference to objective facts in the external world than ordinary beliefs do. The possibility that I take $p$ to be shared with you, whereas you do not believe $p$ or do not take $p$ to be shared with me may give rise to various kinds of failures, misunderstandings, or deceptions, but creates no more epistemological difficulties than standard private beliefs do. Therefore, Sperber and Wilson's (1986) objections against the concept of mutuality do not apply to this account.

The intention to communicate is subject to the same kind of analysis: for the reasons we have just viewed with respect to shared belief, it cannot be defined as a conjunction of private intentions. Airenti, Bara, and Colombetti (1993) instead define communicative intention as another primitive mental state type: in particular, as an agent's intention to overtly make some of her mental states (including the communicative intention itself) shared with a partner.

Shared beliefs, private beliefs, and communicative intentions partake in a specific cognitive dynamic, dubbed the conversation game by the authors, that accounts for the process whereby an agent understands a partner's communicative act and generates an appropriate response. The conversation game consists in a sequence of defeasible inferences and metainferences leading from the agent's comprehension of the literal meaning of the utterance to his comprehension of its pragmatic meaning, to a consequent modification of his mental states about the domain of discourse, and finally to the planning and the generation of a response. The whole process is given a detailed formal account in a descriptive logic of mental states.

Technicalities aside, the key points made by Airenti, Bara, and Colombetti (1993), from the viewpoint of our current discussion, are their arguments that communication requires a dedicated set of mental states (namely, shared belief and communicative intention) and that the mental events underlying it consist in a dedicated cognitive dynamic (that is, a specific, well-identifiable sequence of mental states).

Given the framework I have described in "Intentional Cognitive Architectures," the ability to communicate thus meets the requirements for being considered as competence, that is, as a specific cognitive subsystem, or faculty. $^{3}$

To say that human communication is competence does not mean that it has to result from the activity of a module, at least in Fodor's (1983) acceptance of what a module is. Modules are blind, rigid, mandatory, "informationally encapsulated" input systems in charge of providing central cognition with the raw material needed to form representations; the typical representatives are language and vision as they are conceived of in classic Chomskyan

${ }^{3}$ No discussion of the architecture of the mind/brain is found in Airenti, Bara, and Colombetti's (1993) paper. The responsibility for this interpretation of their work is therefore solely mine. 
linguistics or in Marr's (1982) theory. As explicitly theorized by Fodor himself (1983), a modular view of input systems can peacefully coexist with a domain-general conception of "central" cognition.

Communication, however, is a flexible, inferential, deliberative activity that cannot be yielded by the functioning of a module: it has therefore be conceived of as the province of Intentional cognition. At the same time, it requires a dedicated competence, made up of specialized Intentional primitives that find their exclusive role in it. (Actually, it would make no sense for an intelligent but nonsocial species to entertain these architectural characteristics.) Thus, the domain-specific view of the architecture of the mind/ brain that I am proposing questions the existence of a general-purpose, equipotential central system, not of the modules.

\section{A THEORY OF COMMUNICATIVE COMPETENCE}

\section{An Architecture for Communication}

Another account of communicative competence has been proposed by me (Tirassa, 1997). This work is, as yet, rather underdeveloped in comparison with that of Airenti, Bara, and Colombetti (1993); however, it explicitly takes architectural issues into account, proposing a domain-specific perspective on the mind/brain.

The theory is based on the agent's rather than the understander's perspective. An agent is defined as an Intentional, conscious organism who lives in a situation (that is, a subjective, open, and changeable interpretation of the world) and strives to make it more to her liking. Although her knowledge of the situation can never be complete, she can improve it by zooming in (or out) on the environment, by reasoning from previous knowledge, and so on. The situation thus evolves in accordance to the agent's knowledge and interests as well as to the changes she perceives in the world.

The agent has to be situated, that is, her mind/brain has to be coupled to the dynamics of the world. Situativity is necessary because of the impossibility for the agent to forecast and anticipate all the possible evolutions of the current situation and is in turn made possible by the rejection of the information-processing postulate on the nature of cognition in favor of a biologically based conception of the mind/brain (see "Mind/Brain Dynamics"; Searle, 1983, 1992; Tirassa, 1994, 1999).

Communication is an overt attempt to reach a situation which is relatively satisfactory to all the participants. An agent's situativity in communication consists in a coupling between the cognitive dynamics she entertains and that she ascribes to the partners. Communication thus depends on the agentbased subjective ontology that is typical of a socially sophisticated species like ours and can be described as mindreading plus communicative planning 
with no need to resort to the fixed set of behavior-based scripts that is instead a common feature of most theories of dialogue. ${ }^{4}$

The cognitive dynamic underlying communication is described as the interplay of several epistemic and volitional primitives. The former comprise beliefs and shared beliefs; the latter comprise desires, future-directed intentions, and present-directed intentions. Given the current interpretation of the situation, desires are involved in the generation of future-directed intentions; the latter control whole segments of dialogue and are involved in their turn in the generation of present-directed intentions that finally control the generation of single communicative acts. A further mental state type of liking is defined that deals with the choice between the various courses of action possible at each level, thus playing the role of a highly simplified motivational system.

An agent's actions in dialogue consist, within the scope of her futuredirected intentions, in a turn-by-turn generation of suitable present-directed intentions to communicate along with feedback revision of her relevant desires and future-directed intentions. The whole process depends on the interaction of this cognitive dynamic with that she ascribes to her partner: she will act so to push the interaction toward a situation that she considers relatively satisfactory.

Since the same description applies to each participant, communication may be viewed as the cooperative construction of a situation that is relatively satisfactory to all the agents involved. Each agent will keep the conversation up as long as she considers this useful and possible; that is, as long as she believes that it may bring some worthy improvement in her situation and that her partner is still willing to interact in his turn.

\section{The Innate Bases of Communicative Competence}

An early, innate version of the Intentional primitives of communication can be shown to be necessary and sufficient for communication in the infant, thus lending further support to a view of communication as competence.

Current theories of pragmatics, as we have seen, build on each agent's capability of comprehending and representing the other's cognitive dynamics. However, the experimental literature agrees that mindreading does not appear before the 3rd or 4th birthday (Baron-Cohen, 1995; Clements \& Perner, 1994; Perner, 1991; Wellman, 1990). On a strictly Gricean account, the implausible consequence is either that children under this age resort to a different mode of communication (which would require in turn a non-Gricean theory

\footnotetext{
${ }^{4}$ The capability of representing and reasoning upon another individual's mental states is often called Theory of Mind. Some authors prefer mindreading because it does not suggest that this ability has to depend on explicit or theoretical reasoning. This is also my choice.
} 
of infant communication plus a theory of the transition from infant to adult communication) or that they simply do not communicate at all.

Francesca Bosco and I have argued that this dilemma can be escaped by viewing communication as an innate competence, two components of which-namely, shared beliefs and communicative intentions-are present at birth, albeit in an early version, while a third-namely, mindreadingappears at a later age (Bosco \& Tirassa, 1998). On our account, agent-based infant communication in the absence of mindreading is then possible if the child simply construes all of her mental states as shared with the caregivers.

This is in full agreement with the experimental literature mentioned above to the effect that the infant is incapable of understanding that other individuals have mental states of their own that are qualitatively similar but not necessarily identical to those that she entertains. While the classic interpretation of these data is that she must therefore live alone in a world of which she is the only inhabitant endowed with a mind, ours is that she lives instead in an ever-social world where everybody is simply and directly aware of her feelings and "thoughts." In her perspective, all of her experiential states would thus be intrinsically public, that is, shared with the individuals that surround her.

The second mental state type that has to be present at birth is an early version of communicative intention. Communicative intention is an agent's intention to overtly modify the situation shared with a partner, that is, her capability of acting so that the partner will notice her actions and ascribe them a suitable communicative meaning. If, as we hypothesize, the child shares the whole of her subjective reality with the partners, then every action she will perform will take place in the cognitive space she shares with them and will therefore have a communicative meaning.

On our account, thus, an infant simply has no private, noncommunicative mental states; to her, communication is a plain state of the world rather than a matter of choice or deliberation. This only requires a primitive recognition of agency, a capability that, according to the relevant literature, can be safely ascribed to infants not older than a few weeks (Leslie, 1994; Premack, 1990). An adult's, or an elder child's, ability to not construe all of her mental states as shared is instead made possible by the later development of mindreading; that is, of the capability of differentiating one's own mental states from those that may be ascribed to the partner.

\section{NEUROPRAGMATICS}

So far, this discussion has been mostly analytical. To be sure, this is partly due to my scientific concerns, that are, admittedly, primarily theoretical. But another, more general reason is that little evidence can as yet be reported in favor of or against the general framework I have outlined-and even less in favor of or against specific (classes of) theories within it. 
Theoretical pragmatics is far from reaching a consensus on even its own fundamentals; furthermore, much research takes place in areas that, like philosophy or artificial intelligence, have a limited interest, if any, in the actual functioning of the human mind/brain. On the other hand, empirical research has often not been guided by clear, well-expressed theories; what is worse, even when such theories are available, the generation and evaluation of precise predictions is an intricate and debatable matter.

In this section I submit a few considerations about how cognitive pragmatics and neuropsychology may bear on each other. In this perspective, there are at least four related main assumptions of my theoretical framework that may lend themselves to empirical scrutiny: (1) communication is independent of the expressive means that are employed in its service; (2) communication may be dealt with in Intentional terms; (3) communication requires specific Intentional primitives; and (4) communication is a faculty, or domain.

These four assumptions are discussed in their turn in the rest of this section. My readings of the evidence currently available are hardly compelling; what I want to show, however, is not so much that one theory fares better than another, but that some evidence is available and that more can be collected with an adequate scientific effort.

\section{Communication Is Independent of the Expressive Means Employed}

Of the four issues mentioned, this is the less problematic from an empirical point of view, given the double dissociability of language and communication.

Aphasia is a selective damage to (part of) an individual's linguistic skills that, however, often affects only mildly the effectiveness of her communication: the array of expressive means employed undergoes restructuring based on a creative use of the remaining linguistic and paralinguistic abilities as well as of gestures, drawings, and so on (de Bleser \& Weisman, 1986; Feyereisen \& Seron, 1982; Guilford \& O'Connor, 1982; Holland, 1982; Joanette \& Brownell, 1991; Penn, 1987; Penn \& Cleary, 1988; Wilcox, Albyn, \& Leonard, 1978). The impairment is so specific to language that even the overall organization of discourse is often substantially spared (Caplan, 1992). These observations have made the focus of rehabilitation shift from the attempt to simply restore linguistic functions to new approaches aimed at enhancing the overall effectiveness of the individual's communication via the mastery of all the expressive channels available (Davis \& Wilcox, 1981, 1985; Howard \& Hatfield, 1987).

Conversely, nonaphasic impairments in communication are often observed after certain types of brain damage, like strokes to the right hemisphere in a left-handed individual or head trauma. As regards the latter, for example, Bruno Bara, Marina Zettin, and I investigated the communicative 
abilities of a group of closed-head injured subjects from which individuals showing any symptom of aphasia had been excluded (Bara, Tirassa, \& Zettin, 1997). The protocol we devised investigated the subjects' understanding of simple linguistic interactions taking place between couple of characters in a series of brief videotaped scenes.

The subjects scored significantly lower than the controls on each scene but the simplest. Even more interestingly, the theory we used for reference (Airenti, Bara, \& Colombetti, 1993) allowed us to draw principled predictions of which types of interactions the subjects would find more and less difficult to understand and therefore to order them in a trend of difficulty going from direct speech acts, to simple indirect speech acts, to complex indirect speech acts, to ironies, and finally to deceits. These predictions were confirmed by the data.

Also, the results we obtained on direct and indirect speech acts (see "Communication Requires Specific Intentional Primitives" below) showed that mere language comprehension is not sufficient, even in the simplest situation, for the understanding of pragmatic meaning - that is, that there always is more to communication than just language.

All these different bodies of empirical evidence are easily explained if communication as a cognitive process is taken to be independent of superficial means of expression. This position also fits well with the basic tenets of Chomskyan linguistics (that views language as a distinct, modular faculty) as well as with data from developmental pragmatics (Airenti, 1998; Bara, Bosco, \& Bucciarelli, 1999; Trevarthen \& Hubley, 1978) and cognitive ethology (Burling, 1993; Premack, 1986) to the effect that infants and possibly, in their own way, nonhuman primates are capable of Intentional communication in spite of their lack of properly linguistic abilities.

\section{Communication May Be Dealt with in Intentional Terms}

The Intentional framework I have outlined for communication (as well as for cognition at large) may seem empirically unwarranted from the start (see also the discussion in "Intentionality and Intentional Primitives"). While it is an obvious fact that beliefs and intentions cannot be observed, however, it may be remarked that the same is true of all the theoretical entities of classical cognitive science: mental models, visuospatial sketchpads, and universal grammars are no more directly observable than beliefs and intentions. The explanatory framework is a matter of initial choice and scientific results, and I have already argued that the Intentional one is particularly fitting for the description of complex agent/world interactions, including communication. The real problems arise instead when one tries to develop a specific theory within the explanatory framework one has chosen.

Thus, the issue is not to prove that mental states exist, but to understand what they are, what Intentional primitives make up the cognitive architecture 
that our species has evolved, which of them are involved in each specific type of agent/world interactions, and how.

The work of Bara, Tirassa, and Zettin (1997) is, at least to my knowledge, the only one in empirical pragmatics that takes an explicitly Intentional standpoint. In this perspective, it seems to me to fare rather well. As said in the previous section, we were able to find a reliable trend in the respective difficulty of several pragmatic phenomena and, in general, most of our predictions were confirmed by the data. What is important here is that these predictions had been drawn from an Intentionality-based theory of communication and with no more recourse to introspection than is usual in psychology or neuropsychology.

\section{Communication Requires Specific Intentional Primitives}

This issue relates to the possibility of testing specific predictions based on different Intentional theories of the same pragmatic phenomenon and may be viewed as an extension and reformulation of what has been said so far in this section.

Some of the predictions in Bara, Tirassa, and Zettin (1997) depended crucially on our theoretical position that shared beliefs and communicative intentions are among the Intentional primitives necessary for communication. These predictions regarded in particular irony and deceits and were all confirmed; that is, the corresponding parts of the theory were not falsified.

As for the actual cognitive dynamic involved in communication, our predictions on direct vs indirect speech acts were grounded in Airenti, Bara, and Colombetti's (1993) account of the conversation game. We found no evidence that direct speech acts (like "Close the window") are easier to understand than the corresponding indirect ones (like "Can you close the window?'). The only reasonable explanation of our data was that there is no such thing as a direct speech act, that is, that the comprehension of the literal meaning of an utterance-provided that an utterance has a literal meaning, a postulate that is in itself questionable - is never sufficient for the comprehension of its pragmatic meaning.

These data were thus in agreement with our theory, but contrasted with the previous neuropsychological literature on the topic (see Stemmer, 1994, for a critical review) that subscribed instead to Searle's (1979) classic view that "direct" speech acts require no processing beyond the comprehension of the literal meaning and are therefore easier to understand than "indirect", ones.

\section{Communication Is a Faculty}

Of the four empirical issues discussed in this section, this is by far the most difficult to test. The question is whether Intentional communication is but an aspect of the functioning of a domain-general cognitive system à la 
Fodor (1975, 1983; Fodor \& Pylyshyn, 1989), as is granted by most theories of pragmatics, or a distinct faculty, as is proposed in this article. Part of the empirical argument in favor of a domain-specific view of communication may be provided by the discussion in the previous subsection, but is there any more direct evidence available?

Several studies of left- and right-hemisphere damage have been conducted in the attempt to identify the brain areas involved in communication (e.g., Foldi, 1987; Foldi, Cicone, \& Gardner, 1983; Joanette, Goulet, Ska, \& Nespoulous, 1986; Kasher, 1991c; Plum, 1988; Sherratt \& Penn, 1990; Weylman, Brownell, Roman, \& Gardner, 1989; Winner \& Gardner, 1977). The relevance of this endeavor to our current discussion comes from the possibility to investigate into the overall function of these areas, once they have been individuated: e.g., the idea of a communicative faculty would be strengthened if they were not substantially involved in other competencies.

To date, unfortunately, the only clear result emerging from this body of literature is that the areas involved in communication are not the same as those that are involved in language. This brings further evidence in favor of a clear distinction between these two cognitive functions (see "Communication Is Independent of the Expressive Means Employed') but will not be of much help to us now: what is at issue here is not whether the language module is anatomically or functionally dissociable from higher-level competencies, but whether the latter are yielded by the activity of a Fodorian domain-general central system or of an assembly of domain-specific, albeit not modular, faculties. The dissociability of communication and language tells us nothing about this.

Let us instead consider again what happens in closed-head injured individuals. According to several clinical observations, their conversation is often incoherent, disorganized, and clogged by irrelevant details and digressions (McDonald, 1992; McDonald \& van Sommers, 1993). What is of interest to us here is that this impairment is permanent, that is, it endures even after a more or less satisfactory recovery of other cognitive functions (Ehrlich \& Barry, 1989; Mentis \& Prutting, 1987; Wyckoff, 1984). This can easily be explained if communication is viewed as a distinct competence, but not if it is viewed as just performance, that is, as an unspecific aspect of the functioning of a general-purpose central system.

A convergent suggestion to the same effect is provided by our work in Bara, Tirassa, and Zettin (1997) that failed to find any significant correlation between the performance of closed-head injured individuals on the communicative protocol and their performance on several neuropsychological tests for working memory, attention, frontal lobe functions, and "general intelligence" (WAIS).

To be sure, neither of these observations proves that communication is a faculty. On the other hand, a view of communication as a domain-specific faculty does not allow for clear-cut double dissociations from other high- 
level competencies, as is instead the case with rigidly encapsulated modules like language. Moreover, even if these data were to be confirmed beyond doubt, they would not rule out an interpretation of pragmatics as the emergent product of the activity of several autonomous modules, whose individual functioning is unrelated to communication. It must be remarked, however, that no theorist seems to endorse this view.

\section{CONCLUSIONS}

I hope I have been able to provide an overview of an area that is open to many developments as well as to complex and unexpected connections to other parts of cognitive science.

Much work has still to be done in theoretical as well as in empirical pragmatics. With regard to the former, I have argued that the most interesting developments are likely to come from the links to current research on the nature and the architecture of cognition, that is, from a view of communication as something that real agents do in the service of goals they pursue in their overall interaction with the real world. Given my theoretical analysis and the independent evidence that the architecture of cognition is domainspecific, I have also argued in favor of the view that communication is a distinct faculty, or competence. Reciprocally, a domain-specific conception of so important a type of agent/world interaction together with the peculiar kind of description provided of it-namely, an Intentional one-is likely to yield valuable consequences on our overall conception of what a mind is and how it can be described.

With regard to empirical pragmatics, I have tried to suggest a few directions of convergence between the analytical and the neuropsychological studies of communication. What we find here is the well-known circularity between the theory and the experiment. On the one hand, the study of how a faculty decays after brain damage is incredibly fascinating and a source of compelling feedback on theoretically motivated positions. On the other hand, it is only from sticking close to clear, well-defined theories that informative and reliable predictions can be generated and tested.

\section{REFERENCES}

Airenti, G. 1998. Dialogue in a developmental perspective. In S. Cmejrková, J. Hoffmannová, O. Müllerová, \& J. Svetlá (Eds.), Proceedings of the 6th Conference of the International Association for Dialogue Analysis, Prague 1996. Tübingen: Niemeyer.

Airenti, G., Bara, B. G., \& Colombetti, M. 1993. Conversation and behavior games in the pragmatics of dialogue. Cognitive Science, 17, 197-256.

Austin, J. L. 1962. How to do things with words (2nd ed., revised by J. O. Ormson \& M. Sbisà, 1975). London: Oxford Univ. Press.

Bara, B. G., Bosco, F. M., \& Bucciarelli, M. 1999. Developmental pragmatics in normal and abnormal children. Brain and Language, 68, 507-528. 
Bara, B. G., Tirassa, M., \& Zettin, M. 1997. Neuropragmatics: Neuropsychological constraints on formal theories of dialogue. Brain and Language, 59, 7-49.

Barkow, J. H., Cosmides, L., \& Tooby, J. (Eds.). 1992. The adapted mind. Evolutionary psychology and the generation of culture. Oxford: Oxford Univ. Press.

Baron-Cohen, S. 1995. Mindblindness. An essay on autism and theory of mind. Cambridge, MA: MIT Press.

Bosco, F. M., \& Tirassa, M. 1998. Sharedness as an innate basis for communication in the infant. In M. A. Gernsbacher \& S. J. Derry (Eds.), Proceedings of the 20th Annual Conference of the Cognitive Science Society (Madison, WI). Mahwah, NJ: Erlbaum.

Bratman, M. E. 1987. Intentions, plans, and practical reason. Cambridge, MA: Harvard Univ. Press.

Burling, R. 1993. Primate calls, human language, and nonverbal communication. Current Anthropology, 343, 25-53.

Caplan, D. 1992. Language: Structure, processing, and disorders. Cambridge, MA: MIT Press.

Chomsky, N. 1980. Rules and representations. New York: Columbia Univ. Press.

Churchland, P. M. 1984. Matter and consciousness: A contemporary introduction to the philosophy of mind. Cambridge, MA: MIT Press.

Churchland, P. M. 1988. The ontological status of intentional states: Nailing folk psychology to its perch. Behavioral and Brain Sciences, 11, 507-508.

Churchland, P. S. 1986. Neurophilosophy: Toward a unified science of the mind/brain. Cambridge, MA: MIT Press.

Clark, H. H. 1996. Using language. Cambridge: Cambridge Univ. Press.

Clark, H. H., \& Marshall, C. R. 1981. Definite reference and mutual knowledge. In A. K. Joshi, B. L. Webber, \& I. A. Sag (Eds.), Elements of discourse understanding. Cambridge: Cambridge Univ. Press.

Clements, W. A., \& Perner, J. 1994. Implicit understanding of belief. Cognitive Development, 9, 377-395.

Cohen, P. R., \& Levesque, H. J. 1990a. Intention is choice with commitment. Artificial Intelligence, 42, 213-261.

Cohen, P. R., \& Levesque, H. J. 1990b. Rational interaction as the basis for communication. In P. R. Cohen, J. Morgan, \& M. E. Pollack (Eds.), Intentions in communication. Cambridge, MA: MIT Press.

Cosmides, L., \& Tooby, J. 1994a. Origins of domain specificity: The evolution of functional organization. In L. A. Hirschfeld \& S. A. Gelman (Eds.), Mapping the mind: Domain specificity in cognition and culture. Cambridge: Cambridge Univ. Press.

Cosmides, L., \& Tooby, J. 1994b. Beyond intuition and instinct blindness: Toward an evolutionarily rigorous cognitive science. Cognition, 50, 41-77.

Davis, A. G., \& Wilcox, M. J. 1981. Incorporating parameters of natural conversation in aphasia treatment. In R. Chapey (Ed.), Language intervention strategies in adult aphasia. Baltimore, MD: Williams \& Wilkins.

Davis, A. G., \& Wilcox, M. J. 1985. Adult aphasia rehabilitation: Applied pragmatics. Windsor: NFER-Nelson.

de Bleser, R., \& Weisman, H. 1986. The communicative impact of non-fluent aphasia on the dialog behavior of linguistically unimpaired partners. In F. Lowenthal \& F. Vandamme (Eds.), Pragmatics and education. New York: Plenum.

Ehrlich, J., \& Barry, P. 1989. Rating communication behaviours in the head-injured adult. Brain Injury, 3, 193-198. 
Feyereisen, P., \& Seron, X. 1982. Nonverbal communication and aphasia: A review. Brain and Language, 16, 191-236.

Fodor, J. A. 1975. The language of thought. New York: Crowell.

Fodor, J. A. 1983. The modularity of mind. An essay on faculty psychology. Cambridge, MA: MIT Press.

Fodor, J. A., \& Pylyshyn, Z. W. 1988. Connectionism and cognitive architecture: A critical analysis. Cognition, 28, 3-71.

Foldi, N. S. 1987. Appreciation of pragmatic interpretation of indirect commands: Comparison of right and left hemisphere brain damaged patients. Brain and Language, 31, 88-108.

Foldi, N. S., Cicone, M., \& Gardner, H. 1983. Pragmatic aspects of communication in braindamaged patients. In S.J. Segalowitz (Ed.), Language functions and brain organization. New York: Academic Press.

Grice, H. P. 1957. Meaning. The Philosophical Review, 67, 377-388.

Grice, H. P. 1982. Meaning revisited. In N.V. Smith (Ed.), Mutual knowledge. New York: Academic Press.

Grice, H. P. 1989. Studies in the way of words. Cambridge, MA: Harvard Univ. Press.

Guilford, A., \& O'Connor, J. 1982. Pragmatic functions in aphasia. Journal of Communication Disorders, 15, 337-346.

Hirschfeld, L. A., \& Gelman, S. A. (Eds.). 1994. Mapping the mind: Domain specificity in cognition and culture. Cambridge: Cambridge Univ. Press.

Holland, A. 1982. Observing functional communication of aphasic adults. Journal of Speech and Hearing Disorders, 47, 50-56.

Howard, D., \& Hatfield, F.M. 1987. Aphasia therapy: Historical and contemporary issues. Hillsdale, NJ: Erlbaum.

James, W. 1890. The principles of psychology. New York: Holt.

Joanette, Y., \& Brownell, H. H. (Eds.). 1991. Discourse ability in brain damage: Theoretical and empirical perspectives. New York: Springer-Verlag.

Joanette, Y., Goulet, P., Ska, B., \& Nespoulous, J.-L. 1986. Informative content of narrative discourse in right-brain-damaged right-handers. Brain and Language, 29, 81-105.

Johnson-Laird, P. N. 1983. Mental models: Towards a cognitive science of language, inference, and consciousness. Cambridge, UK: Cambridge Univ. Press.

Karmiloff-Smith, A. 1992. Beyond modularity: A developmental perspective on cognitive science. Cambridge, MA: MIT Press.

Kasher, A. 1976. Conversational maxims and rationality. In A. Kasher (Ed.), Language in focus: Foundations, methods, and systems. Dordrecht: Reidel.

Kasher, A. 1991a. Pragmatics and Chomsky's research program. In A. Kasher (Ed.), The Chomskyan turn. Oxford: Blackwell.

Kasher, A. 1991b. Pragmatics and the modularity of the mind. In S. Davis (Ed.), Pragmatics: A reader. Oxford: Oxford Univ. Press.

Kasher, A. 1991c. On the pragmatic modules: A lecture. Journal of Pragmatics, 16, 381397.

Leslie, A. M. 1994. ToMM, ToBy, and Agency: Core architecture and domain specificity. In L. A. Hirschfeld \& S. A. Gelman (Eds.), Mapping the mind: Domain specificity in cognition and culture. Cambridge: Cambridge Univ. Press.

Marr, D. 1982. Vision: A computational investigation into the human representation and processing of visual information. San Francisco: Freeman.

Mentis, M., \& Prutting, C. A. 1987. Cohesion in the discourse of normal and head injured adults. Journal of Speech and Hearing Research, 30, 88-98. 
McDonald, S. 1992. Differential pragmatic language loss after closed head injury: Ability to comprehend conversational implicature. Applied Psycholinguistics, 13, 295-312.

McDonald, S., \& van Sommers, P. 1993. Pragmatic language skills after closed head injury: Ability to negotiate requests. Cognitive Neuropsychology, 10, 297-315.

Minsky, M. 1985. The society of mind. New York: Simon \& Schuster.

Newell, A. 1990. Unified theories of cognition. Harvard, MA: Harvard Univ. Press.

Newell, A., \& Simon, H. A. 1972. Human problem solving. Englewood Cliffs, NJ: PrenticeHall.

Penn, C. 1987. Compensation and language recovery in the chronic aphasic patient. Aphasiology, 1, 235-245.

Penn, C., \& Cleary, J. 1988. Compensatory strategies in the language of closed head injured patients. Brain Injury, 1, 3-17.

Perner, J. 1991. Understanding the representational mind. Cambridge, MA: MIT Press.

Pinker, S. 1997. How the mind works. Harmondsworth, UK: Penguin.

Plum, F. (Ed.) 1988. Language, communication, and the brain. New York: Raven.

Pollack, M. E. 1990. Plans as complex mental attitudes. In P. R. Cohen, J. Morgan, \& M. E. Pollack (Eds.), Intentions in communication. Cambridge, MA: MIT Press.

Premack, D. 1990. The infant's theory of self-propelled objects. Cognition, 36, 1-16.

Premack, D. 1986. Gavagai! Or the future history of animal language controversy. Cambridge, MA: MIT Press.

Rao, A., \& Georgeff, M. 1992. An abstract architecture for rational agents. In B. Nebel, C. Rich, \& W. Swartout (Eds.), Proceedings of KR 92: The 3rd International Conference on Knowledge Representation and Reasoning. San Mateo, CA: Morgan Kaufmann.

Schiffer, S. R. 1972. Meaning. Oxford: Oxford Univ. Press.

Searle, J. R. 1969. Speech acts: An essay in the philosophy of language. Cambridge: Cambridge Univ. Press.

Searle, J. R. 1979. Expression and meaning. Cambridge: Cambridge Univ. Press.

Searle, J. R. 1983. Intentionality: An essay in the philosophy of mind. Cambridge: Cambridge Univ. Press.

Searle, J. R. 1992. The rediscovery of the mind. Cambridge, MA: MIT Press.

Sherratt, S. M., \& Penn, C. 1990. Discourse in a right-hemisphere brain-damaged subject. Aphasiology, 4, 539-560.

Spelke, E. 1994. Initial knowledge: Six suggestions. Cognition, 50, 431-445.

Sperber, D., \& Wilson, D. 1986. Relevance. Communication and cognition (2nd ed., 1995). Oxford: Blackwell.

Stemmer, B. 1994. A pragmatic approach to neurolinguistics: Requests (re)considered. Brain and Language, 46, 565-591.

Stich, S. P. 1983. From folk psychology to cognitive science: The case against belief. Cambridge, MA: MIT Press.

Strawson, P. F. 1964. Intention and convention in speech acts. The Philosophical Review, 73, 439-460.

Tirassa, M. 1994. Is consciousness necessary to high-level control systems? [Online]. Psycoloquy, 5, psyc.94.5.82.robot-consciousness.2.tirassa Available <http:// www.princeton.edu/ $\sim$ harnad/psyc.html $>$.

Tirassa, M. 1997. Mental states in communication. In Proceedings of the 2 nd European Conference on Cognitive Science. Manchester, UK. 
Tirassa, M. 1999. Taking the trivial doctrine seriously: Functionalism, eliminativism, and materialism. Behavioral and Brain Sciences.

Tirassa, M., Carassa, A., \& Geminiani, G. (In press). A theoretical framework for the study of spatial cognition. In S. O’Nuallain (Ed.), Spatial cognition. Amsterdam: Benjamins.

Trevarthen, C., \& Hubley, P. 1978. Secondary intersubjectivity: Confidence, confiding and acts of meaning in the first year. In A. Lock (Ed.), Action, gesture, and symbol: The emergence of language. London: Academic Press.

Wellman, H. M. 1990. The child's theory of mind. Cambridge, MA: MIT Press.

Weylman, S. T., Brownell, H. H., Roman, M., \& Gardner, H. 1989. Appreciation of indirect requests by left- and right-brain-damaged patients: The effects of verbal context and conventionality of wording. Brain and Language, 36, 362-377.

Wilcox, M. J., Albyn, D. G., \& Leonard, L. B. 1978. Aphasics' comprehension of contextually conveyed meaning. Brain and Language, 6, 362-377.

Wilson, D., \& Sperber, D. 1991. Pragmatics and modularity. In S. Davis (Ed.), Pragmatics: A reader. Oxford: Oxford Univ. Press.

Winner, E., \& Gardner, H. 1977. The comprehension of metaphor in brain-damaged patients. Brain, 100, 719-727.

Wyckoff, L. H. 1984. Narrative and procedural discourse following closed head injury. Unpublished doctoral dissertation, University of Florida. 